OPEN ACCESS

Edited by:

Oriol Bestard,

Bellvitge University Hospital, Spain

Reviewed by:

Lionel Couzi,

Université de Bordeaux, France

Jakob Nilsson,

University Hospital Zürich, Switzerland

*Correspondence:

Marcia M. L. Kho

m.kho@erasmusmc.nl

Specialty section:

This article was submitted to Alloimmunity and Transplantation,

a section of the journal

Frontiers in Immunology

Received: 06 January 2021 Accepted: 01 March 2021

Published: 18 March 2021

Citation:

Kho MML, Roest S, Bovée DM, Metselaar HJ, Hoek RAS, van der Eijk AA, Manintveld OC, Roodnat JI and van Besouw NM (2021) Herpes

Zoster in Solid Organ Transplantation: Incidence and Risk Factors.

Front. Immunol. 12:645718.

doi: 10.3389/fimmu.2021.645718

\section{Herpes Zoster in Solid Organ Transplantation: Incidence and Risk Factors}

\author{
Marcia M. L. Kho ${ }^{1,2 *}$, Stefan Roest ${ }^{2,3}$, Dominique M. Bovée ${ }^{1,2}$, Herold J. Metselaar ${ }^{2,4}$, \\ Rogier A. S. Hoek ${ }^{2,5}$, Annemiek A. van der Eijk ${ }^{6}$, Olivier C. Manintveld ${ }^{2,3}$, \\ Joke I. Roodnat ${ }^{1,2}$ and Nicole M. van Besouw ${ }^{1,2}$ \\ 1 Department of Internal Medicine-Nephrology and Transplantation, Erasmus MC, University Medical Centre Rotterdam, \\ Rotterdam, Netherlands, ${ }^{2}$ Erasmus MC Transplant Institute, University Medical Center Rotterdam, Rotterdam, Netherlands, \\ ${ }^{3}$ Department of Cardiology, Thorax Center, Erasmus MC, University Medical Centre Rotterdam, Rotterdam, Netherlands, \\ ${ }^{4}$ Department of Gastroenterology and Hepatology, Erasmus MC, University Medical Centre Rotterdam, Rotterdam, \\ Netherlands, ${ }^{5}$ Department of Respiratory Medicine, Erasmus MC, University Medical Centre Rotterdam, Rotterdam, \\ Netherlands, ${ }^{6}$ Department of Viroscience, Erasmus MC, University Medical Centre Rotterdam, Rotterdam, Netherlands
}

Background: Studies on herpes zoster $(\mathrm{HZ})$ incidence in solid organ transplant (SOT) recipients report widely varying numbers. We investigated $\mathrm{HZ}$ incidence, severity, and risk factors in recipients of four different SOTs, with a follow-up time of 6-14 years.

Methods: Records of 1,033 transplant recipients after first heart (HTx: $n=211)$, lung (LuTx: $n=121$ ), liver (LiTx: $n=258$ ) and kidney (KTx: $n=443$ ) transplantation between 2000 and 2014 were analyzed for VZV-PCR, clinical signs of HZ, and complications.

Results: HZ was diagnosed in 108 of 1,033 patients (10.5\%): 36 HTx, 17 LuTx, 15 LiTx, and $40 \mathrm{KTx}$ recipients. Overall $\mathrm{HZ}$ incidence rate after $\mathrm{HTx}$ (30.7 cases/1,000 personyears (PY)), LuTx (38.8 cases/1,000 PY), LiTx (22.7 cases/1,000 PY) and KTx (14.5 cases/ 1,000 PY) was significantly higher than in the general $50-70$ year population. Multivariable analysis demonstrated age $\geq 50$ years at transplantation ( $p=0.038, R R 1.536$ ), type of organ transplant (overall $p=0.002$; LuTx $p=0.393$; RR 1.314; LiTx $p=0.011$, RR 0.444; $K T x p=0.034$, RR 0.575), CMV prophylaxis ( $p=0.043$, RR 0.631) and type of antirejection therapy (overall $p=0.020$; methylprednisolone $p=0.008$, RR 0.475; $r$-ATG $\mathrm{p}=0.64, \mathrm{RR} 1.194)$ as significant risk factors. Complications occurred in 33 of 108 (31\%) patients (39\% of HTx, $47 \%$ of LuTx, $20 \%$ of LiTx, $20 \%$ of KTx): post-herpetic neuralgia, disseminated disease, and cranial nerve involvement.

Conclusion: $\mathrm{HZ}$ incidence and severity in SOT recipients are most pronounced after heart and lung transplantation, in older patients, and when CMV prophylaxis is lacking.

Keywords: herpes zoster, incidence, organ transplantation, risk factors, varicella zoster virus 


\section{INTRODUCTION}

Herpes zoster (shingles, HZ) is caused by reactivation of the varicella zoster virus (VZV). After primary infection, the virus establishes lifelong latency in the dorsal root neural ganglia (1). Virus reactivation occurs when the immune system is suppressed. Increased $\mathrm{HZ}$ incidence, attributed to a decline in immunity, is observed in elderly people and in patients using immunosuppressive medication (2-10). The latter certainly applies to solid organ transplant recipients.

Both HZ incidence and HZ related complications occur more frequently and with higher severity in solid organ transplant recipients compared to the general population (11). Severe complications are dissemination in more than three dermatomas, involvement of cranial nerves or internal organs and post-herpetic neuralgia (PHN). PHN may lead to considerable morbidity and loss of quality of life (12). Due to the use of different definitions of PHN, the reported incidence ranges from 10 to $50 \%$ of herpes zoster cases (13). In the Netherlands, overall annual HZ incidence is 3.2 cases per 1,000 person-years (PY), comparable to other West-European countries (3). HZ incidence increases with age up to 10 cases/ 1,000 PY (3) in people older than 80 years. In solid organ recipients however, $\mathrm{HZ}$ incidence has been reported to be twoto five-fold higher than in the general 80 years old population (14-18).

Studies on HZ incidence and complications in multiple solid organ transplant (SOT) recipients report widely varying numbers. In North America and Asia $\mathrm{HZ}$ incidence ranges from 18/1,000 PY in liver to 55/1,000 PY in lung transplant recipients (14-21). Whereas in Europe, kidney transplant studies show crude incidences of $1-8 \%(22,23)$ and overall incidences of 20/1,000 PY (24), and one study of multiple SOT recipients reports an incidence of 12/1,000 PY (25). Therefore, we assessed crude and overall incidence and complications of $\mathrm{HZ}$ after heart, lung, liver, and kidney transplantation in our center by retrospective analysis of the medical files of adult recipients. Furthermore, we performed a detailed analysis of risk factors for developing HZ.

\section{PATIENTS AND METHODS}

Medical records of adult heart (HTx), lung (LuTx), liver (LiTx), and kidney $(\mathrm{KTx})$ transplant recipients in our transplant center between 2000 and 2014 were reviewed. Permission to extract data from the hospital (pharmacy) records was granted by the local medical ethical commission: MEC-2018-1574. Because not all KTx recipients visit our outpatient clinic in case of infection, we performed an inquiry by letter and phone calls. Patients who

Abbreviations: ABO-I, ABO-blood type incompatible; CMV, cytomegalovirus; DCD, donation after cardiac death; HZ, herpes zoster; HTx, heart transplantation; LiTx, liver transplantation; LuTx, lung transplantation; KTx, kidney transplantation; PCR, polymerase chain reaction; PHN, post-herpetic neuralgia; PY, person years; r-ATG, rabbit anti-thymocyte globulin; SOT, solid organ transplantation; Tx, transplantation; VZV, varicella zoster virus. died or lost their graft within one month after a first organ transplantation were excluded from our analysis. KTx recipients whose medical records were incomplete, mostly due to referral to another hospital, and who did not respond to our inquiries, were excluded (Figure 1).

Demographic and clinical information was extracted from the medical records and included the following information: transplantation date, gender, date of birth, date of death or graft failure (if applicable), duration of follow-up, induction therapy, maintenance immunosuppressive regimen, use of methylprednisolone or rabbit Anti-Thymocyte Globulin (r-ATG) as anti-rejection therapy, cytomegalovirus (CMV) prophylaxis regimen, serum CMV-PCR results post-transplantation, patient CMV serologic status pretransplantation, donor CMV serologic status, patient VZV serologic status (IgG positive or negative) pre-transplantation, first episode of $\mathrm{HZ}$, location and number of dermatomas affected by HZ, internal organ and cranial nerve involvement, VZV-PCR results, therapy used to treat $\mathrm{HZ}$, and occurrence of PHN. Primary varicella zoster infections were not included in our analysis.

Localized $\mathrm{HZ}$ was defined as presentation of vesicles in one or two adjacent dermatomas, whereas involvement of three or more, or two not adjacent dermatomas was considered as disseminated HZ (11). Cranial nerve involvement was scored separately. Post-herpetic neuralgia (PHN) was defined as pain in the affected dermatomas, persisting at least 3 months after onset of the skin lesions and requiring treatment with opioid analgesics, tricyclic antidepressants, gabapentin, or pregabalin (26). Infections were mostly confirmed by VZV-PCR on the blood and/or blister samples; however, in obvious cases $\mathrm{HZ}$ was diagnosed on clinical presentation only.

\section{Statistical Analysis}

Analyses were performed in SPSS, version 25, 2017. HZ incidence was expressed as percentage of the total number of patients (crude incidence) and as cases per 1,000 person-years (overall incidence rate). Age at transplantation in all patients with and without $\mathrm{HZ}$ was compared by one-way ANOVA. Age at transplantation in patients with positive and negative VZV IgG before transplantation was also compared by one-way ANOVA. Correlation between time to HZ onset and age at transplantation was analyzed with Spearman's correlation test. Univariable and multivariable Cox proportional hazards analysis using backward elimination was used to analyze the effect of multiple variables on $\mathrm{HZ}$ incidence. Univariable Cox proportional hazards analysis was used to analyze the effect of the type of organ transplant on complicated $\mathrm{HZ}$ incidence. Cases with missing values were excluded from Cox proportional hazards analyses.

\section{RESULTS}

\section{Patient Characteristics}

In total, 1,261 patients received a first transplant, of which $235 \mathrm{HTx}$ (Tx period January 2000-July 2014), 127 LuTx (Tx period April 2002-March 2014), 276 LTx (Tx period January 2008-July 2014), 


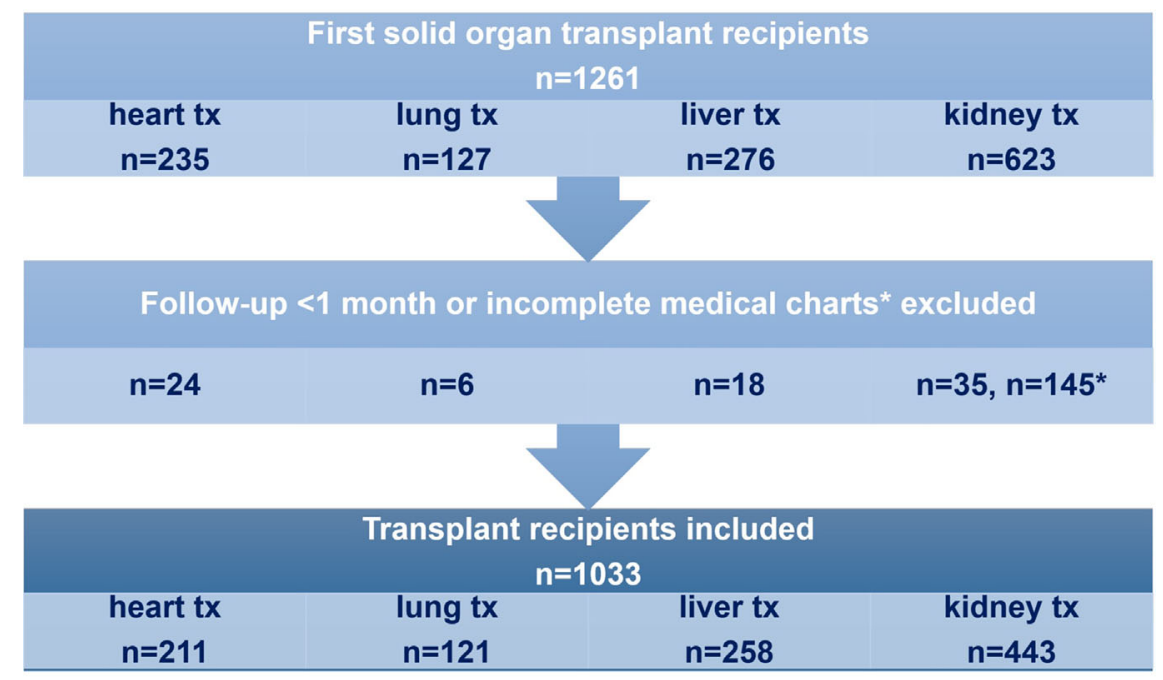

FIGURE 1 | Adult recipients of a first solid organ transplant with a minimum follow-up of 1 month and complete medical charts were included in the analysis. tx $=$ transplantation.

and $623 \mathrm{KTx}$ (Tx period January 2003-January 2009). Of the 588 KTx patients with a follow-up of more than 1 month, 145 had incomplete medical charts, due to referral to another hospital and/or no response to our inquiry, resulting in 443 patients in the KTx group and a total of 1,033 patients (Figure 1). Maximum follow-up time was 14 years in HTx, 12 years in LuTx, 6 years in LiTx and 10 years in KTx recipients. Mean follow-up time was 5.5 years in HTx, 3.6 years in LuTx, 2.6 years in LiTx, and 6.0 years in KTx. During follow-up 26 (12\%) HTx, 21 (17\%) LuTx, 29 (11\%) LiTx, and 14 (3\%) KTx recipients died and $12(5 \%)$ LiTx and 72 (16\%) KTx recipients lost their graft.

The characteristics of the organ transplant recipients are shown in Table 1. In the LuTx group about 54\% was male, whereas in the other groups the percentage of males varied between 62 and $68 \%$. The standard immunosuppressive medication regimens at time of transplantation in each group are shown in Table $\mathbf{1}$. There are some differences in immunosuppressive medication between the transplant groups: all HTx recipients received $\mathrm{r}$-ATG as induction therapy. After LiTx, patients received tacrolimus monotherapy as maintenance immunosuppressive therapy from 6 months post-transplantation. HTx and LuTx recipients received an increased dose of maintenance immunosuppression as compared to LiTx and KTx recipients (triple therapy including low dose prednisolone and higher tacrolimus target concentrations).

In general, valganciclovir was used as CMV prophylaxis. In the LuTx and KTx groups, all except CMV donor negative/recipient negative combinations received prophylaxis. In the HTx and LiTx groups only CMV donor positive/recipient negative combinations received prophylaxis. In the HTx group up to 2003, prophylactic anti-CMV immunoglobulin was given in the first 6 weeks after transplantation. Since 2003, valganciclovir was given during the first 6 months after transplantation. In the LuTx group, duration of CMV prophylaxis was extended during the study period: up to 2012 valganciclovir was given during the first 3 months, since 2012 prophylaxis was extended to 6 months after transplantation. In the KTx and LiTx groups, valganciclovir was given during the first 3 months.

Most of the methylprednisolone treated rejections occurred early after transplantation, during the standard CMV prophylaxis period: 59/72 (82\%) in HTx, 25/42 (60\%) in LuTx, 14/30 (47\%) in LiTx, 65/102 (64\%) in KTx. CMV prophylaxis was not extended after methylprednisolone anti-rejection treatment.

\section{VZV-Seroprevalence}

In the Netherlands, no routine VZV vaccination program exists, neither primary vaccination for the general population nor booster vaccination for senior adults. VZV is endemic in the Dutch population, seroprevalence of VZV antibodies amounts to 95\% (27). Of our transplant candidates 3.7\% (38/1033) was VZV seronegative prior to transplantation (Table 1).

Age at transplantation was significantly higher in patients who were VZV IgG seropositive compared to seronegative before transplantation [50.4 (17.5-77.8) vs. 45.7 (19.7-75.2), $\mathrm{p}=0.024]$.

Two KTx patients, one LuTx patient, and two HTx patients suffered from primary VZV infection, 1.2-8 years after transplantation. Although some had severe complications, none of them died.

Pre-transplantation vaccination of VZV seronegative patients was introduced only in the kidney transplant group [two doses of Provarivax (Merck Sharp \& Dohme B.V., Haarlem) (28)]. Four of $15 \mathrm{VZV}$-seronegative kidney transplant candidates were vaccinated before transplantation with Provarivax. One of these vaccinated transplant recipients developed $\mathrm{HZ}$ during follow-up, at 2.7 years post-transplantation. This patient had non-complicated $\mathrm{HZ}$ and recovered without sequelae. 
TABLE 1 | Transplant recipients' characteristics.

\begin{tabular}{|c|c|c|c|c|c|}
\hline Organ transplant & Heart & Lung & Liver & Kidney & Overall \\
\hline Recipients in analysis & 211 & 121 & 258 & 443 & 1033 \\
\hline Gender (M/F) & $143 / 68$ & $65 / 56$ & $169 / 89$ & 274/169 & $649 / 384$ \\
\hline Median age at Tx (range) & $51(18-72)$ & $54(19-66)$ & $53(18-69)$ & $51(18-77)$ & $52(18-77)$ \\
\hline Age $\geq 50 y$ at $\mathrm{Tx}(\%)$ & $54 \%$ & $66 \%$ & $58 \%$ & $53 \%$ & $56 \%$ \\
\hline Pre-Tx VZV-IgG pos/neg/unknown & $194 / 11 / 6$ & $108 / 5 / 8$ & $239 / 7 / 12$ & $419 / 15 / 9$ & $960 / 38 / 35$ \\
\hline Induction therapy & r-ATG211 (100\%) & Basiliximab 121 (100\%) & Basiliximab258 (100\%) & $\begin{array}{l}\text { 2006-2008: rATG in DCD: } 44 \\
\text { (10\%) Rituximab in ABO-I: } 18 \\
\text { (4\%) No induction: } 381 \text { (86\%) }\end{array}$ & \\
\hline $\begin{array}{l}\text { Standard maintenance } \\
\text { immunosuppression > } 6 \text { months }\end{array}$ & $\begin{array}{c}\text { Tacrolimus + } \\
\text { Mycophenolate Mofetil + } \\
\text { Prednisolone }\end{array}$ & $\begin{array}{c}\text { Tacrolimus + } \\
\text { Mycophenolate Mofetil + } \\
\text { Prednisolone }\end{array}$ & Tacrolimus & $\begin{array}{c}\text { Tacrolimus + Mycophenolate } \\
\text { Mofetil }\end{array}$ & \\
\hline $\begin{array}{l}\text { Tacrolimus target trough levels } \\
\text { (ug/l) }\end{array}$ & $\begin{array}{l}<12 \text { mo: } 9-15 \\
>12 \text { mo: } 5-9\end{array}$ & $\begin{array}{l}<7 \text { mo: } 10-15 \\
>7 \text { mo: } 7-10\end{array}$ & $5-8$ & $5-8$ & \\
\hline \multicolumn{6}{|l|}{$>6$ months } \\
\hline r-ATG anti-rejection therapy (pts) & $15(7 \%)$ & 0 & $1(0.4 \%)$ & $32(7 \%)$ & $48(5 \%)$ \\
\hline $\begin{array}{l}\text { Methylprednisolone anti-rejection } \\
\text { therapy (pts) }\end{array}$ & $72(34 \%)$ & $42(35 \%)$ & $30(12 \%)$ & $102(23 \%)$ & $246(24 \%)$ \\
\hline \multicolumn{6}{|l|}{ CMV serostatus pre-transplant } \\
\hline D-/R- & $36(17 \%)$ & $30(25 \%)$ & 44 (17\%) & 96 (22\%) & $206(20 \%)$ \\
\hline D-/R+ & 71 (34\%) & 37 (31\%) & $80(31 \%)$ & $102(23 \%)$ & $290(28 \%)$ \\
\hline D+/R- & $59(28 \%)$ & 23 (19\%) & $45(17 \%)$ & 82 (19\%) & 209 (20\%) \\
\hline $\mathrm{D}+/ \mathrm{R}+$ & 45 (21\%) & $30(25 \%)$ & 89 (35\%) & $154(35 \%)$ & $318(31 \%)$ \\
\hline unknown & 0 & $1(1 \%)$ & 0 & $9(2 \%)$ & 10 (1\%) \\
\hline \multicolumn{6}{|l|}{ CMV prophylaxis } \\
\hline Yes & $59^{\mathrm{a}}(28 \%)$ & 91 (75\%) & 45 (17\%) & 340 (77\%) & 535 (52\%) \\
\hline No & 152 (72\%) & $30(25 \%)$ & 213 (83\%) & 99 (22\%) & 494 (48\%) \\
\hline unknown & 0 & 0 & 0 & $4(1 \%)$ & $4(1 \%)$ \\
\hline
\end{tabular}

TX, transplantation; M, male; F, female; D, donor; R, recipient; pts, patients; VZV-lgG, Varicella Zoster Virus immunoglobulin G; r-ATG, rabbit anti-thymocyte globulin; Basiliximab, InterLeukin2-receptor blocker; Rituximab, anti-CD20 antibody; DCD, donation after cardiac death. ${ }^{a}$ : five patients received immunoglobulin CMV prophylaxis.

Booster vaccination of seropositive patients was not performed in any of the groups.

\section{Incidence and Severity of Herpes Zoster}

To compare the incidence of $\mathrm{HZ}$ in our center with the incidence reported by other authors, we analyzed both crude and overall incidences. Only the first $\mathrm{HZ}$ episode after transplantation was analyzed. Primary VZV infections were not included in the analysis.

The crude HZ incidence was 36/211 (17.1\%) in the heart, $17 /$ $121(14.0 \%)$ in the lung, $15 / 258(5.8 \%)$ in the liver, and $40 / 443$ (9.2\%) in the kidney transplant recipients (Table 2).

The overall HZ incidence is shown in Table 2 as the number of $\mathrm{HZ}$ cases per 1,000 person-years (PY), meaning the years at risk of $\mathrm{HZ}$ after transplantation. The $\mathrm{HZ}$ incidence was significantly higher after HTx (30.7 cases/1,000 PY) compared to after LiTx (22.7 cases/1,000 PY) and after KTx (14.5 cases/ 1,000 PY) (Cox proportional hazards, $\mathrm{p}<0.001$ in LiTx vs. HTx, $\mathrm{p}=0.003$ in KTx $v s$. HTx). HZ incidence after LuTx (38.8 cases/ $1,000 \mathrm{PY}$ ) was comparable after HTx (Cox proportional hazards, $\mathrm{p}=0.907$ ) (Tables 2 and 4, Figure 2).

The median time to the onset of HZ was 2.0 years after HTx, 1.4 years after LuTx, 0.5 years after LiTx, and 1.8 years after KTx (Table 2).

More than $80 \%$ of $\mathrm{HZ}$ episodes were treated with oral valacyclovir (Table 2). LuTx recipients more often received intravenous acyclovir treatment compared to recipients of other organs.
Complicated HZ incidence did not significantly differ between the four organ transplant groups (Cox proportional hazards, $\mathrm{p}=0.156$ ) (Table 3). The incidences of PHN, disseminated $\mathrm{HZ}$, and cranial nerve involvement are shown in Table 3. One LuTx patient and two KTx recipients died due to disseminated HZ with secondary bacterial infection and encephalitis. Of the patients who had HZ after treatment for acute rejection, six had complicated HZ. Four patients (three LuTx, one LiTx) had received methylprednisolone, one HTx and one KTx patient received r-ATG (Table 2).

\section{Risk Factors for Herpes Zoster}

We analyzed the risk factors for the development of HZ. Age at transplantation was not different between patients who did or did not develop HZ, neither in the entire group [51.7 (21.1-72.8) vs. 49.9 (17.5-77.8), p = 0.17), nor in the HTx, LuTx, LiTx, and KTx groups separately.

No correlation was found between the time to the onset of $\mathrm{HZ}$ after transplantation and age at transplantation $\left(r_{s}=0.009\right.$, $\mathrm{p}=0.93)$.

As HZ incidence significantly increases in the general population above 50 years (3), we added age categories $\geq 50$ years and $\geq 60$ years at transplantation as dichotomous variables. We studied the effect of the following variables on the risk of developing HZ: gender, age at transplantation, age $\geq 50$ years at transplantation, age $\geq 60$ years at transplantation, type of organ transplant, use of methylprednisolone or r-ATG anti-rejection therapy, induction therapy agent (no induction, basiliximab, 
TABLE 2 | Transplant recipients with herpes zoster.

\begin{tabular}{|c|c|c|c|c|c|}
\hline Organ transplant & Heart & Lung & Liver & Kidney & Overall \\
\hline \multicolumn{5}{|l|}{ Cases/recipients } & 108/1033 (10.5\%) \\
\hline \multicolumn{6}{|l|}{ Cases/1,000 PY } \\
\hline Gender (M / F) & $27 / 9$ & $9 / 8$ & $11 / 4$ & $25 / 15$ & $72 / 36$ \\
\hline Median age at Tx (range) & $54(22-67)$ & $60(35-67)$ & $52(22-60)$ & $53(28-77)$ & $53(21-72)$ \\
\hline $\mathrm{HZ}$ onset post-Tx & $2.0(0.04-10.8)$ & $1.4(0.08-3.8)$ & $0.5(0.3-4.5)$ & $1.8(0.04-8.9)$ & $1.2(0.04-10.8)$ \\
\hline \multicolumn{6}{|l|}{ Median years (range) } \\
\hline \multicolumn{6}{|l|}{ Initial HZ treatment } \\
\hline Oral & 32 (89\%) & 9 (53\%) & 12 (80\%) & 37 (92\%) & $90(83 \%)$ \\
\hline Intravenous & $4(11 \%)$ & 7 (41\%) & $3(20 \%)$ & $3(8 \%)$ & 17 (16\%) \\
\hline No treatment & 0 & $1(6 \%)$ & 0 & 0 & $1(1 \%)$ \\
\hline \multicolumn{6}{|l|}{ CMV-IgG pre-Tx } \\
\hline D-/R- & $5(14 \%)$ & 5 (29\%) & $3(20 \%)$ & $10(25 \%)$ & $23(21 \%)$ \\
\hline D-/R+ & 19 (53\%) & 7 (41\%) & $5(33 \%)$ & $7(18 \%)$ & 38 (35\%) \\
\hline D+/R- & 7 (19\%) & $3(18 \%)$ & $1(7 \%)$ & $6(15 \%)$ & $17(16 \%)$ \\
\hline D+/R+ & $5(14 \%)$ & $2(12 \%)$ & $6(40 \%)$ & $16(40 \%)$ & $29(27 \%)$ \\
\hline unknown & 0 & 0 & 0 & $1(3 \%)$ & $1(1 \%)$ \\
\hline \multicolumn{6}{|l|}{ CMV prophylaxis } \\
\hline Yes & $7(19 \%)$ & $12(71 \%)$ & $1(7 \%)$ & $28(70 \%)$ & $48(44 \%)$ \\
\hline No & $29(81 \%)$ & $5(8 \%)$ & $14(23 \%)$ & $11(28 \%)$ & 59 (54\%) \\
\hline unknown & 0 & 0 & 0 & $1(3 \%)$ & $1(1 \%)$ \\
\hline \multirow[t]{2}{*}{ Induction therapy } & r-ATG & Basiliximab & Basiliximab & 2006-2008: rATG in DCD: 2 (5\%) & r-ATG 38 (35\%) \\
\hline & $36(100 \%)$ & 17 (100\%) & 15 (100\%) & $\begin{array}{c}\text { Rituximab in ABO-I: } 3 \text { (7.5\%) } \\
\text { No induction: } \\
35 \text { (87.5\%) }\end{array}$ & $\begin{array}{c}\text { Basiliximab } 32(30 \%) \\
\text { Rituximab } 3(3 \%) \\
\text { No } 35(32 \%)\end{array}$ \\
\hline prior r-ATG anti-rejection therapy & $3(8 \%)^{a}$ & 0 & 0 & $5(13 \%)^{a}$ & $8(7 \%)$ \\
\hline prior methylprednisolone anti-rejection therapy & $3(8 \%)$ & $5(29 \%)^{b}$ & $3(20 \%)^{a}$ & $5(13 \%)$ & $16(15 \%)$ \\
\hline
\end{tabular}

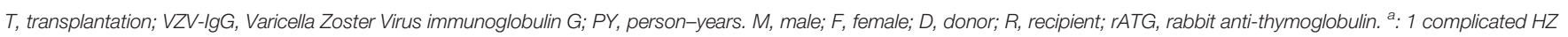
case. ${ }^{b}$ : 3 complicated $\mathrm{HZ}$ cases.

rATG, or rituximab), use of CMV prophylaxis (in all patients and in CMV seropositive recipients only), duration of CMV prophylaxis (none, valganciclovir 3 months, and $\geq 6$ months), occurrence of CMV viremia (serum CMV-PCR >1000 IU/ml) and pre-transplant VZV-IgG (positive of negative) (Tables 4 and 5).

In univariable Cox regression analysis, age $\geq 50$ years at transplantation, type of organ transplant, use of CMV prophylaxis, duration of CMV prophylaxis, use of induction therapy, type of induction therapy, and type of anti-rejection therapy significantly influenced the risk of developing $\mathrm{HZ}$ (Table 4).

In multivariable Cox regression analysis, successively including all the above mentioned variables, age $\geq 50$ years at transplantation, type of organ transplant, use of CMV prophylaxis, and type of anti-rejection therapy were the variables significantly influencing the risk of developing HZ (Table 5). Patients $\geq 50$ years of age had a significantly increased risk of developing $\mathrm{HZ}$ compared to younger patients $(\mathrm{p}=0.038, \mathrm{RR}=1.536, \mathrm{CI}=1.023-2.304)$. Compared to HTx (reference variable) the risk of HZ after LuTx was not different. The risk of developing HZ after $\operatorname{LiTx}(\mathrm{p}=0.011$, $\mathrm{RR}=0.444, \mathrm{CI}=0.237-0.833)$ and after $\mathrm{KTx}(\mathrm{p}=0.034$, $\mathrm{RR}=0.575, \mathrm{CI}=0.345-0.959)$ was significantly lower than after HTx (Figure 2, Table 5). Use of CMV prophylaxis significantly diminished HZ risk $(\mathrm{p}=0.043, \mathrm{RR}=0.631, \mathrm{CI}=0.40-0.986)$. The risk of developing $\mathrm{HZ}$ was significantly lower in patients who were treated for acute rejection with methylprednisolone, compared to those without acute rejection treatment $(\mathrm{p}=0.008, \mathrm{RR}=0.475$, $\mathrm{CI}=0.275-0.821$ ). In the multivariable Cox regression model, no interaction was found between type of organ transplant and either age $\geq 50$ years, use of CMV prophylaxis, or type of antirejection therapy.

In addition, we performed a Cox regression analysis of the effect of the above mentioned variables on the risk of developing $\mathrm{HZ}$ in all organ transplant subgroups. In the LuTx and LiTx groups, none of the variables significantly influenced the incidence of HZ. In univariable analysis in the HTx group ( $\mathrm{n}=211$ with $36 \mathrm{HZ}$ cases) we found two significant risk factors for development of HZ: any anti-rejection therapy ( $\mathrm{p}=$ 0.002 , RR $0.253(0.105-0.610)$ and type of anti-rejection therapy (overall $\mathrm{p}=0.009$; methylprednisolone $\mathrm{p}=0.003, \mathrm{RR} 0.165$ (0.050-0.542); rATG $\mathrm{p}=0.311$, RR 0.541 (0.164-1.778). In univariable analysis in $\mathrm{CMV}$ seropositive $\mathrm{KTx}$ recipients ( $\mathrm{n}=256,23 \mathrm{HZ}$ cases), use of CMV prophylaxis significantly reduced the incidence of $\mathrm{HZ}(\mathrm{p}=0.0001, \mathrm{RR}=0.109, \mathrm{CI}=$ $0.032-0.371)$.

\section{DISCUSSION}

Our study is one of the largest European studies that report the incidence and severity of $\mathrm{HZ}$ in recipients of four solid organ transplants with a maximum follow-up time of 14 years in HTx, 12 years in LuTx, 6 years in LiTx, and 10 years in KTx 
TABLE 3 | Herpes zoster complications.

\begin{tabular}{|c|c|c|c|c|c|}
\hline Organ transplant & Heart & Lung & Liver & Kidney & Overall \\
\hline Complicated/Total & 14/36 (39\%) & $8 / 17$ (47\%) & $3 / 15(20 \%)$ & $8 / 40(20 \%)$ & $33 / 108(31 \%)$ \\
\hline RR $(95 \% \mathrm{Cl}) \mathrm{p}$-value & Reference & $2.147(0.831-5.550) 0.115$ & $1.166(0.314-4.326) 0.818$ & $0.671(0.269-1.670) 0.391$ & 0.156 \\
\hline Post Herpetic Neuralgia & 7 (19\%) & $3(18 \%)$ & $1(7 \%)$ & 0 & $11(33 \%)$ \\
\hline Disseminated disease & $2(6 \%)$ & 5 (29\%) & $2(13 \%)$ & $7(18 \%)$ & $16(48 \%)$ \\
\hline Cranial nerve involvement & $5(14 \%)$ & $1(6 \%)$ & 0 & $1(3 \%)$ & $7(21 \%)$ \\
\hline Deceased due to complicated $\mathrm{HZ}$ & 0 & $1(6 \%)$ & 0 & $2(5 \%)$ & $3(9 \%)$ \\
\hline
\end{tabular}

recipients. In addition, risk factors for the development of $\mathrm{HZ}$ were analyzed.

The crude $\mathrm{HZ}$ incidence was $17.1 \%$ in the heart, $14.0 \%$ in the lung, $5.8 \%$ in the liver, and $9.2 \%$ in the kidney transplant recipients. The overall HZ incidence in HTx (30.7 cases/1,000 PY) and LuTx (38.8 cases/1,000 PY) recipients was significantly higher compared to LiTx (22.7 cases/1,000 PY) and KTx (14.5 cases/1,000 PY) recipients.

Overall and crude HZ incidence rates in our KTx group are lower than the reports of KTx recipients from Canada and the

TABLE 4 | Risk factors for herpes zoster, univariable analysis.

\begin{tabular}{|c|c|c|}
\hline \multirow[t]{2}{*}{ Variable (reference) } & \multicolumn{2}{|c|}{$\begin{array}{l}\text { Cox proportional hazards } \\
\text { Univariable analysis }\end{array}$} \\
\hline & RR $(95 \% \mathrm{Cl})$ & p-value \\
\hline Gender (male) & $0.834(0.559-1.245)$ & 0.374 \\
\hline Age (continuous) & $1.012(0.997-1.028)$ & 0.125 \\
\hline Age $\geq 50$ years & $1.672(1.120-2.495)$ & 0.012 \\
\hline Age $\geq 60$ years & $1.355(0.889-2.066)$ & 0.158 \\
\hline Organ transplant (Heart) & & 0.003 \\
\hline Lung & $1.035(0.579-1.850)$ & 0.907 \\
\hline Liver & $0.300(0.159-0.565)$ & $<0.001$ \\
\hline Kidney & $0.482(0.297-0.783)$ & 0.003 \\
\hline VZV IgG pre-transplant (negative) & $2.370(0.585-9.611)$ & 0.227 \\
\hline Valganciclovir CMV prophylaxis (no) & $0.629(0.430-0.922)$ & 0.017 \\
\hline CMV prophylaxis (no) & & 0.041 \\
\hline Valganciclovir 3 months & $0.603(0.404-0.900)$ & 0.013 \\
\hline Valganciclovir $>6$ months & $0.669(0.289-1.547)$ & 0.347 \\
\hline CMV prophylaxis (no) & & 0.086 \\
\hline Valganciclovir 3 months & $0.603(0.405-0.900)$ & 0.013 \\
\hline Valganciclovir 6 months & $0.752(0.302-1.872)$ & 0.540 \\
\hline Valganciclovir 9 months & $0.430(0.059-3.115)$ & 0.403 \\
\hline Valganciclovir prophylaxis CMV R+ (no $)^{a}$ & $0.550(0.337-0.898)$ & 0.017 \\
\hline CMV-PCR >1,000 IU/ml & $1.012(0.627-1.634)$ & 0.960 \\
\hline Induction therapy (no) & $1.676(1.114-2.522)$ & 0.013 \\
\hline Induction therapy (no) & & 0.035 \\
\hline Basiliximab or Rituximab & $1.537(0.952-2.482)$ & 0.078 \\
\hline rATG & $1.818(1.144-2.887)$ & 0.011 \\
\hline Induction therapy (no) & & 0.059 \\
\hline Basiliximab & $1.484(0.909-2.423)$ & 0.114 \\
\hline rATG & $1.817(1.144-2.886)$ & 0.011 \\
\hline Rituximab & $2.432(0.746-7.928)$ & 0.140 \\
\hline Anti-rejection therapy (no) & & 0.042 \\
\hline Methylprednisolone & $0.531(0.311-0.906)$ & 0.020 \\
\hline r-ATG & $1.301(0.629-2.691)$ & 0.477 \\
\hline r-ATG anti-rejection therapy (no) & $1.481(0.720-3.050)$ & 0.286 \\
\hline
\end{tabular}

VZV IgG, varicella zoster virus specific immunoglobulin G; CMV, cytomegalovirus; $r$-ATG, rabbit anti-thymocyte globulin; CMV R+, CMV seropositive recipient.

${ }^{a} \mathrm{CMV}$ seropositive recipients without Valganciclovir prophylaxis were compared to CMV seropositive recipients with Valganciclovir prophylaxis.
USA, but higher than those from other European countries (14-16, 20, 22-25). HZ incidence in our LiTx group is higher than in previous studies $(15,19)$. These differences may be explained by a higher percentage of patients in North-America using T-cell depleting induction therapy and a more intense maintenance immunosuppressive regimen. In addition, in other European and Asian countries, the duration of CMV prophylaxis in KTx and LiTx patients is longer compared to our center. In our HTx and LuTx groups, HZ incidence is lower than in other studies $(15,17,18,21)$, which might be due to a longer duration of CMV prophylaxis in our transplant recipients and lower tacrolimus target trough levels after 1 year post-transplantation.

HTx, LuTx, and LiTx patients with infectious problems generally visit the outpatient transplant clinic. However, KTx recipients may visit their general practitioner and may go unnoticed. Therefore, KTx recipients wer also contacted by letter and by telephone. This resulted in a more reliable incidence and a more complete picture of $\mathrm{HZ}$ complications (e.g. PHN) compared to earlier studies that lacked this approach.

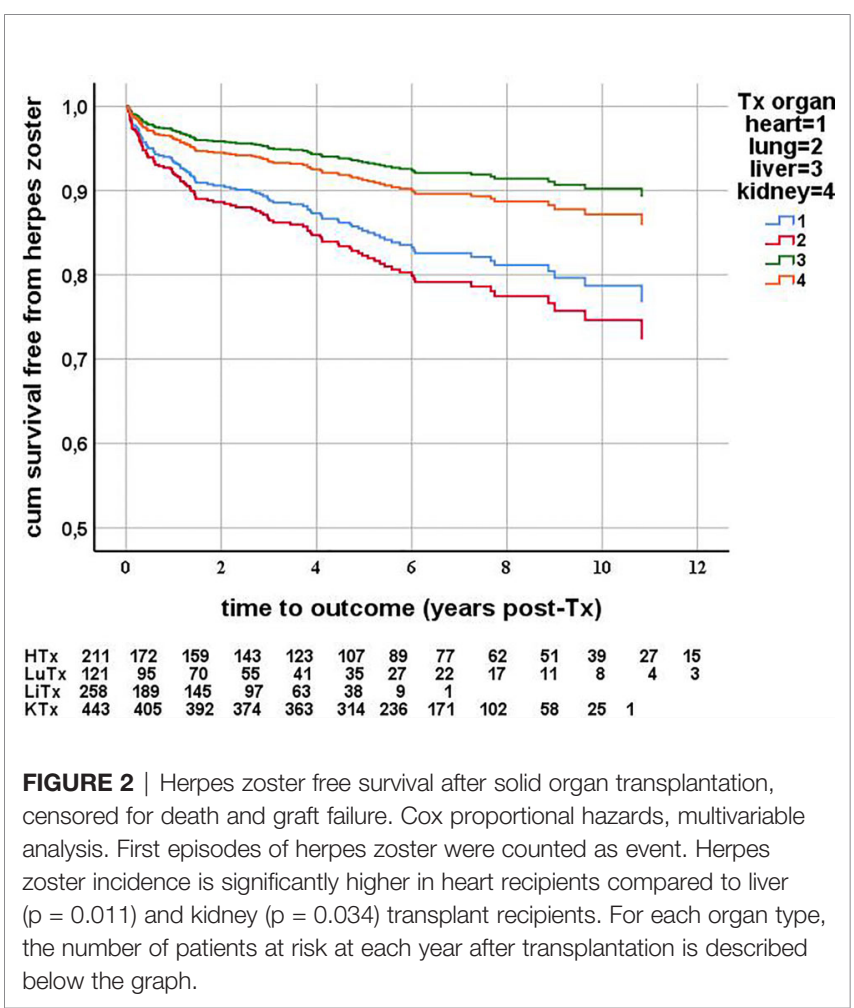


TABLE 5 | Risk factors for herpes zoster, multivariable analysis.

\begin{tabular}{|c|c|c|}
\hline \multirow[t]{2}{*}{ Variable (reference) } & \multicolumn{2}{|c|}{$\begin{array}{l}\text { Cox proportional hazards Multivariable } \\
\text { analysis }\end{array}$} \\
\hline & RR (95\% Cl) & p-value \\
\hline Age ( $\geq 50$ years) & $1.536(1.023-2.304)$ & 0.038 \\
\hline Organ transplant (Heart) & & 0.002 \\
\hline Lung & $1.314(0.703-2.455)$ & 0.393 \\
\hline Liver & $0.444(0.372-0.833)$ & 0.011 \\
\hline Kidney & $0.575(0.345-0.959)$ & 0.034 \\
\hline CMV prophylaxis (no) & $0.631(0.404-0.986)$ & 0.043 \\
\hline Anti-rejection therapy (no) & & 0.020 \\
\hline Methylprednisolone & $0.475(0.275-0.821)$ & 0.008 \\
\hline r-ATG & $1.194(0.566-2.518)$ & 0.641 \\
\hline
\end{tabular}

CMV, cytomegalovirus; r-ATG, rabbit anti-thymocyte globulin.

In addition to crude and overall incidences of HZ, our study also focused on severity of HZ. Post-herpetic neuralgia (PHN) and other complications of $\mathrm{HZ}$ are not uniformly described in the literature. In our study, PHN, dissemination, and cranial nerve involvement were more often reported in HTx and LuTx compared to KTx recipients. PHN incidence, as indicated in Table 3, is lower than in other reports. This is probably due to our more strict definition of PHN: $>3$ months PHN plus requirement of either opioid analgesics, tricyclic antidepressants, gabapentin, or pregabalin. The incidence of disseminated $\mathrm{HZ}$ was higher compared to other reports $(14-19,23)$. However, the definition of dissemination was not specified in these reports.

Furthermore, we analyzed potential risk factors for HZ. In the multivariate analysis, type of organ transplant, age $\geq 50$ years at transplantation, duration of CMV prophylaxis, and type of antirejection therapy significantly influenced the risk of developing $\mathrm{HZ}$ (Table 5). As expected, the risk of HZ is higher in HTx and LuTx recipients, who are exposed to higher levels of immunosuppressive maintenance therapy. However, HZ incidence after KTx or LiTx is still significantly higher compared to healthy individuals (age $<40$ years: two cases/ 1,000 PY, age 40-50 years: 1-4/1,000 PY, age 50-70: 7-8/1,000 PY and age $>80$ years: $10 / 1,000$ PY) (3). VZV and CMV are both herpes viruses; therefore CMV prophylaxis strategies might influence the incidence of HZ. Ko et al. found a lower HZ incidence per 1,000 PY in KTx patients who received $>3$ months prophylaxis compared to patients who received pre-emptive therapy (20). However, Fernandez-Ruiz et al. and MartinGandul et al. did not show a significant effect of CMV prophylaxis on $\mathrm{HZ}$ incidence compared to pre-emptive therapy $(23,25)$. In our study, patients using CMV prophylaxis did have a significantly lower risk of HZ. We did not find a significant effect of longer use of CMV prophylaxis on $\mathrm{HZ}$ incidence, but the number of patients receiving at least 6 months of prophylaxis (84 patients) may be too low to find significant effects. In our center herpes simplex prophylaxis with acyclovir is not used.

In other studies, more intensive immunosuppressive therapy was frequently reported as risk factor for HZ: anti-rejection treatment $(21,24)$, induction therapy (mostly anti-thymocyte globulin) (16), and use of mycophenolate mofetil $(17,19)$. Surprisingly, we found that in patients treated for acute rejection with methylprednisolone, the risk of $\mathrm{HZ}$ was lower than in patients who did not experience acute rejection. Sixteen out of 246 patients with methylprednisolone treated rejection developed HZ. We should not make assumptions due to these low numbers. However, our finding could be explained by the fact that most (overall 66\%) of the methylprednisolone treated rejections occurred during the standard CMV prophylaxis period. Methylprednisolone could have diminished acute neuritis, although studies on steroid treatment of herpetic neuralgia show conflicting results $(29,30)$. Valganciclovir could have suppressed zoster virus reactivation in an early stage. Asymptomatic virus reactivations would then go unnoticed, but could have boosted the immune system. Another possible explanation is that patients experiencing rejection received an insufficient amount of immunosuppression and were therefore less immunocompromised compared to patients who did not experience rejection. More potent anti-rejection therapy with r-ATG was not a significant risk factor, possibly due to the low number of patients (eight of 48 with r-ATG developed HZ). Induction therapy no longer remained significant as risk factor for $\mathrm{HZ}$ after multivariable analysis. In our study, type of organ transplant appeared the most powerful risk factor for HZ. The higher level of maintenance immunosuppressive medication (higher tacrolimus target trough levels) is a probable explanation. However, type of organ transplant could also reflect more than the difference in immunosuppressive burden, but a more detailed analysis of patient's frailty and co-morbidity is needed to confirm that hypothesis.

There are some limitations to our study. First, the patients included in the KTx and LiTx groups received their transplantation in different time periods compared to the HTx and LuTx groups. However, maintenance immunosuppression and CMV prophylaxis were comparable in all groups. Only induction therapy differed in the KTx group. Data on dosing of maintenance immunosuppression per patient were not analyzed due to the retrospective approach and large number of patients in this study. However, the target trough levels in each organ group are described in Table 2. Finally, we did not analyze renal function after solid organ transplantation as risk factor for HZ. Patients with end stage renal disease show premature aging of the T-cell system (31), and a higher $\mathrm{HZ}$ incidence in patients with chronic renal insufficiency has been reported $(32,33)$.

Vaccination has been shown to be effective in the prevention of $\mathrm{HZ}$ in healthy elderly people (34-36) as well as in patients with chronic kidney disease $(37,38)$. Currently, there are two licensed $\mathrm{HZ}$ vaccines. One is a live attenuated vaccine (34), which cannot be given to patients using immunosuppressive medication for fear of inducing VZV infection. The other is a subunit vaccine, containing VZV glycoprotein E (35), which could be given to patients on immunosuppressive medication, because it does not contain live virus. One phase III trial of the subunit vaccine in renal transplant recipients has shown persisting humoral and cell-mediated immunity at one year after vaccination (39). More studies are necessary to confirm that this vaccine is an effective tool to prevent $\mathrm{HZ}$ in organ transplant recipients. 
In summary, this study shows that incidence of $\mathrm{HZ}$ is high after organ transplantation with severe complications. The incidence of HZ after HTx or LuTx is significantly higher than after LiTx or KTx. Use of CMV prophylaxis significantly decreases $\mathrm{HZ}$ incidence. A rational method to prevent $\mathrm{HZ}$ after organ transplantation might be to use CMV prophylaxis, and in our opinion booster vaccination in seropositive transplant candidates is advisable.

\section{DATA AVAILABILITY STATEMENT}

The data analyzed in this study is subject to the following licenses/restrictions: The data were derived from hospital charts and hospital pharmacy records. Requests to access these datasets should be directed to m.kho@erasmusmc.nl.

\section{ETHICS STATEMENT}

The studies involving human participants were reviewed and approved by the Medisch Ethische Toetsings Commissie, Erasmus Medical Center, Rotterdam, Netherlands. Written

\section{REFERENCES}

1. Zerboni L, Sen N, Oliver SL, Arvin AM. Molecular mechanisms of varicella zoster virus pathogenesis. Nat Rev Microbiol (2014) 12(3):197-210. doi: 10.1038/nrmicro3215

2. Blumberg EA, Molavi A. Herpes zoster. Clin Dermatol (1989) 7(1):37-48. doi: 10.1016/0738-081X(89)90027-8

3. Pinchinat S, Cebrian-Cuenca AM, Bricout H, Johnson RW. Similar herpes zoster incidence across Europe: results from a systematic literature review. BMC Infect Dis (2013) 13:170. doi: 10.1186/1471-2334-13-170

4. Helmuth IG, Poulsen A, Suppli CH, Molbak K. Varicella in Europe-A review of the epidemiology and experience with vaccination. Vaccine (2015) 33 (21):2406-13. doi: 10.1016/j.vaccine.2015.03.055

5. Schmidt SA, Kahlert J, Vestergaard M, Schonheyder HC, Sorensen HT. Hospital-based herpes zoster diagnoses in Denmark: rate, patient characteristics, and all-cause mortality. BMC Infect Dis (2016) 16:99. doi: 10.1186/s12879-016-1369-6

6. Zorzoli E, Pica F, Masetti G, Franco E, Volpi A, Gabutti G. Herpes zoster in frail elderly patients: prevalence, impact, management, and preventive strategies. Aging Clin Exp Res (2018) 30(7):693-702. doi: 10.1007/s40520018-0956-3

7. Schroder C, Enders D, Schink T, Riedel O. Incidence of herpes zoster amongst adults varies by severity of immunosuppression. J Infect (2017) 75(3):207-15. doi: 10.1016/j.jinf.2017.06.010

8. Singh N, Gayowski T, Yu VL. Herpes zoster-associated idiopathic thrombocytopenic purpura in a liver transplant recipient: a case report and overview. Transpl Int (1995) 8(1):58-60. doi: 10.1111/j.1432-2277.1995.tb01708.x

9. Feng AC, Hsieh CB, Fan HL. Ramsay Hunt syndrome with an unusual clinical presentation in a liver transplant recipient: a case report and literature review. Transpl Int (2013) 26(9):e77-8. doi: 10.1111/tri.12106

10. Muñoz-Quiles C, López-Lacort M, Díez-Domingo J, Orrico-Sánchez A. Herpes zoster risk and burden of disease in immunocompromised populations: a population-based study using health system integrated databases, 2009-2014. BMC Infect Diseases (2020) 20(1):905. doi: 10.1186/ s12879-020-05648-6

11. Pergam SA, Limaye APPractice ASTIDCo. Varicella zoster virus in solid organ transplantation. Am J Transplant (2013) 13 Suppl 4:138-46. doi: 10.1111/ajt.12107 informed consent for participation was not required for this study in accordance with the national legislation and the institutional requirements.

\section{AUTHOR CONTRIBUTIONS}

$\mathrm{MK}$ and NV designed the research, collected, analyzed, and interpreted the data, and prepared the manuscript. SR and DB participated in data collection. JR participated in statistical analysis and preparation of the manuscript. $\mathrm{HM}, \mathrm{RH}, \mathrm{AV}$, and OM participated in interpretation and preparation of the manuscript. All authors contributed to the article and approved the submitted version.

\section{ACKNOWLEDGMENTS}

The authors thank Prof. Dr. T. van Gelder, Prof. Dr. M. Reinders and Dr. D. Hesselink for critically reading the manuscript, Mr. J. Hassink for supplying data from the hospital pharmacy records, and Mrs. W. van der Bent for sorting the data from the hospital pharmacy records.

12. Drolet M, Brisson M, Schmader KE, Levin MJ, Johnson R, Oxman MN, et al. The impact of herpes zoster and postherpetic neuralgia on health-related quality of life: a prospective study. CMAJ (2010) 182(16):1731-6. doi: 10.1503/ cmaj.091711

13. Johnson RW, Wasner G, Saddier P, Baron R. Postherpetic neuralgia: epidemiology, pathophysiology and management. Expert Rev Neurother (2007) 7(11):1581-95. doi: 10.1586/14737175.7.11.1581

14. Arness T, Pedersen R, Dierkhising R, Kremers W, Patel R. Varicella zoster virus-associated disease in adult kidney transplant recipients: incidence and risk-factor analysis. Transpl Infect Dis (2008) 10(4):260-8. doi: 10.1111/ j.1399-3062.2007.00289.x

15. Pergam SA, Forsberg CW, Boeckh MJ, Maynard C, Limaye AP, Wald A, et al. Herpes zoster incidence in a multicenter cohort of solid organ transplant recipients. Transpl Infect Dis (2011) 13(1):15-23. doi: 10.1111/j.13993062.2010.00547.x

16. Gourishankar S, McDermid JC, Jhangri GS, Preiksaitis JK. Herpes zoster infection following solid organ transplantation: incidence, risk factors and outcomes in the current immunosuppressive era. Am J Transpl (2004) 4 (1):108-15. doi: 10.1046/j.1600-6143.2003.00287.x

17. Koo S, Gagne LS, Lee P, Pratibhu PP, James LM, Givertz MM, et al. Incidence and risk factors for herpes zoster following heart transplantation. Transpl Infect Dis (2014) 16(1):17-25. doi: 10.1111/tid.12149

18. Manuel O, Kumar D, Singer LG, Cobos I, Humar A. Incidence and clinical characteristics of herpes zoster after lung transplantation. J Heart Lung Transpl (2008) 27(1):11-6. doi: 10.1016/j.healun.2007.09.028

19. Hamaguchi Y, Mori A, Uemura T, Ogawa K, Fujimoto Y, Okajima H, et al. Incidence and risk factors for herpes zoster in patients undergoing liver transplantation. Transpl Infect Dis (2015) 17(5):671-8. doi: 10.1111/tid.12425

20. Ko GB, Kim T, Kim SH, Choi SH, Kim YS, Woo JH, et al. Increased incidence of herpes zoster in the setting of cytomegalovirus preemptive therapy after kidney transplantation. Transpl Infect Dis (2013) 15(4):416-23. doi: 10.1111/tid.12091

21. La Hoz RM, Wallace A, Barros N, Xie D, Hynan LS, Liu T, et al. Epidemiology and risk factors for varicella zoster virus reactivation in heart transplant recipients. Transpl Infect Dis (2020) 21:e13519. doi: 10.1111/tid.13519

22. Rodriguez-Moreno A, Sanchez-Fructuoso AI, Calvo N, Ridao N, Conesa J, Marques $\mathrm{M}$, et al. Varicella infection in adult renal allograft recipients: experience at one center. Transplant Proc (2006) 38(8):2416-8. doi: 10.1016/j.transproceed.2006.08.060 
23. Fernandez-Ruiz M, Origuen J, Lora D, Lopez-Medrano F, Gonzalez E, Polanco $\mathrm{N}$, et al. Herpes zoster in kidney transplant recipients: protective effect of anti-cytomegalovirus prophylaxis and natural killer cell count. A single-center cohort study. Transpl Int (2018) 31(2):187-97. doi: 10.1111/ tri. 13076

24. Pavlopoulou ID, Poulopoulou S, Melexopoulou C, Papazaharia I, Zavos G, Boletis IN. Incidence and risk factors of herpes zoster among adult renal transplant recipients receiving universal antiviral prophylaxis. BMC Infect Dis (2015) 15:285. doi: 10.1186/s12879-015-1038-1

25. Martin-Gandul C, Stampf S, Hequet D, Mueller NJ, Cusini A, van Delden C, et al. Preventive Strategies Against Cytomegalovirus and Incidence of alphaHerpesvirus Infections in Solid Organ Transplant Recipients: A Nationwide Cohort Study. Am J Transpl (2017) 17(7):1813-22. doi: 10.1111/ajt.14192

26. Johnson RW, Rice ASClinical practice. Postherpetic neuralgia. N Engl J Med (2014) 371(16):1526-33. doi: 10.1056/NEJMcp1403062

27. van Lier A, Smits G, Mollema L, Waaijenborg S, Berbers G, van der Klis F, et al. Varicella zoster virus infection occurs at a relatively young age in The Netherlands. Vaccine (2013) 31(44):5127-33. doi: 10.1016/j.vaccine.2013.08.029

28. Kho MM, Zuijderwijk JM, van der Eijk AA, de Kuiper R, Boer-Verschragen MJ, Weimar W, et al. Humoral and cellular response after varicella vaccination in VZV IgG seronegative kidney transplant candidates. Vaccine (2017) 35(1):71-6. doi: 10.1016/j.vaccine.2016.11.043

29. Wang X, Zhang X, Yu Z, Zhang Q, Huang D, Yu S. Long-term outcomes of varicella zoster virus infection-related myelitis in 10 immunocompetent patients. J Neuroimmunol (2018) 321:36-40. doi: 10.1016/j.jneuroim.2018.05.005

30. Wood MJ, Johnson RW, McKendrick MW, Taylor J, Mandal BK, Crooks J. A randomized trial of acyclovir for 7 days or 21 days with and without prednisolone for treatment of acute herpes zoster. N Engl J Med (1994) 330 (13):896-900. doi: 10.1056/NEJM199403313301304

31. Betjes MG, Langerak AW, van der Spek A, de Wit EA, Litjens NH. Premature aging of circulating $\mathrm{T}$ cells in patients with end-stage renal disease. Kidney Int (2011) 80(2):208-17. doi: 10.1038/ki.2011.110

32. Forbes HJ, Bhaskaran K, Thomas SL, Smeeth L, Clayton T, Langan SM. Quantification of risk factors for herpes zoster: population based case-control study. BMJ (2014) 348:g2911. doi: 10.1136/bmj.g2911

33. Wu MY, Hsu YH, Su CL, Lin YF, Lin HW. Risk of herpes zoster in CKD: a matched-cohort study based on administrative data. Am J Kidney Dis (2012) 60(4):548-52. doi: 10.1053/j.ajkd.2012.03.018
34. Oxman MN, Levin MJ, Johnson GR, Schmader KE, Straus SE, Gelb LD, et al. A vaccine to prevent herpes zoster and postherpetic neuralgia in older adults. N Engl J Med (2005) 352(22):2271-84. doi: 10.1056/ NEJMoa051016

35. Lal H, Cunningham AL, Godeaux O, Chlibek R, Diez-Domingo J, Hwang SJ, et al. Efficacy of an adjuvanted herpes zoster subunit vaccine in older adults. N Engl J Med (2015) 372(22):2087-96. doi: 10.1056/ NEJMoa1501184

36. Tavares-Da-Silva F, Co MM, Dessart C, Herve C, Lopez-Fauqued M, Mahaux O, et al. Review of the initial post-marketing safety surveillance for the recombinant zoster vaccine. Vaccine (2019) 38(18):3489-500. doi: 10.1016/ j.vaccine.2019.11.058

37. Langan SM, Thomas SL, Smeeth L, Margolis DJ, Nitsch D. Zoster vaccination is associated with a reduction of zoster in elderly patients with chronic kidney disease. Nephrol Dial Transpl (2016) 31(12):2095-8. doi: 10.1093/ ndt/gfv432

38. Miller G, Schaefer H, Yoder S, Miller R, Winokur P, Kotloff K, et al. A randomized, placebo-controlled phase I trial of live, attenuated herpes zoster vaccine in subjects with end-stage renal disease immunized prior to renal transplantation. Transpl Infect Dis (2018) 20(3):e12874. doi: 10.1111/ tid. 12874

39. Vink P, Ramon Torrell JM, Sanchez Fructuoso A, Kim SJ, Kim SI, Zaltzman J, et al. Immunogenicity and Safety of the Adjuvanted Recombinant Zoster Vaccine in Chronically Immunosuppressed Adults Following Renal Transplant: A Phase 3, Randomized Clinical Trial. Clin Infect Dis (2020) 70 (2):181-90. doi: doi: 10.1093/cid/ciz177

Conflict of Interest: The authors declare that the research was conducted in the absence of any commercial or financial relationships that could be construed as a potential conflict of interest.

Copyright (c) 2021 Kho, Roest, Bovée, Metselaar, Hoek, van der Eijk, Manintveld, Roodnat and van Besouw. This is an open-access article distributed under the terms of the Creative Commons Attribution License (CC BY). The use, distribution or reproduction in other forums is permitted, provided the original author(s) and the copyright owner(s) are credited and that the original publication in this journal is cited, in accordance with accepted academic practice. No use, distribution or reproduction is permitted which does not comply with these terms. 